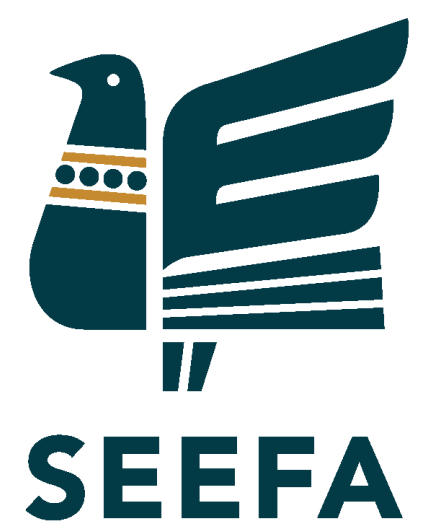

THE SLAVIC, EAST EUROPEAN, AND EURASIAN FOLKLORE ASSOCIATION

\title{
Editor's Note 2019
}

The 2019 edition of Folklorica marks our transition to an all-online format. We are pleased to offer greater access to the journal across the globe, as befits SEEFA's mission. Jim Bailey, the first president of SEEFA, exemplified this trait. The tributes that followed his passing this year highlighted his collaborations with folklorists during the Cold War and beyond it. In his honor, SEEFA has established the James O. Bailey Travel Award to support student travel to the ASEEES annual conference. This journal is the result of Jim's vision, and we are grateful for his support of our discipline and for his profound contributions on Russian folk poetry.

This volume is being produced in the context of a global pandemic and protests for justice across the world in response to the Black Lives Matter movement in the United States and the disputed Belarusian elections, to name just two examples. These timely articles reveal the role that folklorists can play in elucidating the view of the "other," namely minorities within a state. Dorian Juric explores historical texts by Croatian ethnographers studying the coffee culture of fellow Muslim citizens. While the authors had a genuine affection for the foodways under consideration, they approached the question from their own nationalist lens. Jake Zawlacki considers the adaptation of a traditional Kazakh folktale into a seminal animated film during the Soviet period. This film, he argues, helped to establish an idealized version of historical Kazakh ethnic identity that persists today, decades after the fall of the Soviet Union. The power of the Kazakh and Croatian examples to define and yet to restrict the conception of ethnic identity reveals the importance of folklore scholarship. These remind us of our obligation to the folk in a fraught cultural moment across the globe: to convey the world through their eyes, not our own.

Jeanmarie Rouhier-Willoughby, Editor 